University of Windsor

Scholarship at UWindsor

Psychology Publications

Department of Psychology

2016

\title{
Youth Development: An ecological Approach to Identity
}

Kristine J. Ajrouch

Julie Hakim-Larson

University of Windsor

Rand Ramadan Fakih

Follow this and additional works at: https://scholar.uwindsor.ca/psychologypub

Part of the Multicultural Psychology Commons

\section{Recommended Citation}

Ajrouch, Kristine J.; Hakim-Larson, Julie; and Fakih, Rand Ramadan. (2016). Youth Development: An ecological Approach to Identity. Handbook of Arab American Psychology, 91-102.

https://scholar.uwindsor.ca/psychologypub/50

This Contribution to Book is brought to you for free and open access by the Department of Psychology at Scholarship at UWindsor. It has been accepted for inclusion in Psychology Publications by an authorized administrator of Scholarship at UWindsor. For more information, please contact scholarship@uwindsor.ca. 


\title{
7 \\ YOUTH DEVELOPMENT \\ An Ecological Approach to Identity
}

\author{
Kristine J. Ajrouch, Julie Hakim-Larson, and Rand Ramadan Fakih
}

Youth constitutes a fluid age category, generally referencing human development processes that precede adulthood. This chapter considers youth as the period that spans infancy through the age of 24, when basic educational and/or training commitments are generally completed. During this phase of development, individuals experience the process of becoming aware of and negotiating racial, ethnic, and gender identities. The salience of such identities occurs through various agents of socialization, starting at birth. Family constitutes the first influential agent of socialization, teaching children basic ideas of who they are and conveying expectations about their actions and beliefs. As children grow and begin to have contact with others beside family, through school activities and opportunities for peer interactions, they often encounter new ideas about what is expected by those outside their families, ideas that sometimes conflict with parental expectations. Community and media also play an important role in youth development, with their presence beginning at birth, but often growing as children spend increasingly more time outside the family context. The characteristics that an agent of socialization exhibits, and the effects they have on youth, likely vary depending on context.

This chapter examines the process of youth development and the impact of socialization among Arab Americans. The distinctiveness of Arab Americans as an ethnic group stems from the fact that their visibility is intimately tied to events and political instabilities in the Arab world. This reality places them in a uniquely marginal position as "not quite White" (Samhan, 1999), yet not fully accepted as a legal minority (Cainkar, 2009). This wider societal experience provides an overarching context for the study of Arab American youth development within an ecological model. This chapter explores theoretical models for understanding youth identity development, and then reviews research findings related to the ways in which family, peers/school, community, and media play a role in the identities of Arab American youth. This is followed by a case example to illustrate concepts and ideas introduced throughout the chapter. Finally, the chapter concludes with a critique of current research and suggests future directions for better understanding Arab American youth development.

\section{Theoretical Frameworks Addressing Youth Identity Development}

One of the central developmental tasks youth face on their journey to adulthood is the establishment of a stable identity (Erikson, 1968). This task is accomplished through the exploration of various roles and ideals, which ultimately leads to important identity commitment domains including occupation, religion, ideology, and gender roles (Erikson, 1968; Marcia, 1966). To Erikson, the culmination of the process of exploration and commitment leads to an achieved 
ego-identity, which refers to a sense of integration of the self as well as a sense of wholeness that derives from the past while including future goals. The construct of ego-identity incorporates the motivation, emotions, and attitudes that organize the life experiences of the developing young person (Lazarus, 1991).

Marcia (1980) extended Erikson's ego-identity theory by proposing a set of four identity statuses: diffuse, foreclosed, moratorium, and achieved. These statuses describe the processes through which individuals deal with the psychological task of establishing an identity. The criteria for each of these four categories or statuses are based on whether youth have explored alternative goals, values, and beliefs, and have made commitments in important life areas including occupation, ideologies (i.e. political and religious beliefs), and interpersonal values. Individuals who have not yet thought about identity issues and have failed to make commitments across life-defining areas are considered to be diffuse. Individuals who have committed to a particular identity domain but made this commitment by conforming to parental or societal values and beliefs rather than by exploring for themselves alternative options are considered to be foreclosed. On the other hand, individuals who are in the midst of actively evaluating all their options and experimenting with identities and beliefs but have not yet made a decision or commitment are classified as being in moratorium. Finally, an achieved identity represents a status in which individuals have reached a clear sense of self by undergoing identity exploration and making personal commitments to particular goals and beliefs. An achieved identity, considered the most adaptive status, is associated with various markers of psychological wellbeing (Kroger, 2003).

Although Erikson (1968) proposed multiple domains of identity (sexual, religious, political, ideological, and occupational), he emphasized that healthy development results from reconciling and integrating various identities into a single unified, consistent identity. These assumptions have led some researchers to operationalize and treat identity as a global construct (De Haan \& Schulenberg, 1997; Goossens, 2001). Identity integration may be especially complex for Arab American youth because they have various intertwined and competing identities within a single domain (e.g. national identity, ethnic identity, and religious identity) that they must synthesize. In addition, even if integration is achieved, it is not clear whether a single identity, defined as an aggregate of multiple identity components, can explain domain-specific behaviors as well as individuals' adaptations to culture and society within which their lives are embedded. As such, drawing solely on Erikson's theory to conceptualize identity development of Arab American youth may obscure understanding of domain-specific identities that are particularly salient for this group, one of which is ethnic identity.

From a social psychological perspective, one important aspect of identity results from an individual's social group membership (Tajfel, 1981; Tajfel \& Turner, 1986). According to social identity theory, individuals are motivated to develop positive social identities based on their group membership (Tajfel, 1978, 1981; Tajfel \& Turner, 1986). A positive social identity is established when individuals evaluate their ingroup more favorably than the outgroup. In turn, ingroup favoritism leads to higher self-esteem as ingroup members claim the positive characteristics of the group as their own. As such, the group provides them with a sense of belonging to the world and acts as a central source of pride and self-esteem.

However, for members of socially devalued groups, such as Arab Americans, who are often portrayed in an unfavorable light (Sirin et al., 2008) that sometimes includes associations with terrorism (Sirin \& Balsano, 2007), maintaining favorable definitions of group membership may be challenging. If Arab American youth internalize negative stereotypical beliefs and views of their own group from mainstream groups and media, they might be at risk for displaying lower self-esteem and experiencing loss of meaning and a sense of confusion in their lives. However, Tajfel and Turner (1986) proposed that in the face of devaluation of their group, individuals may reinterpret the meaning of their group membership (social identity) by rejecting external judgments and by comparing themselves to the outgroup on a new dimension to which they are superior to reestablish positive distinctiveness (e.g. Arab Americans have higher income and education than Americans, or exhibit higher moral 
standards).Accordingly, based on their socialization experiences and the larger social context in which they live, Arab American youth may adopt either a positive or a negative view of their own group.

Phinney (1989) drew on Tajfel's theory of social identity, Erikson's theory of ego-identity formation, and Marcia's work on ego-identity statuses to conceptualize and measure ethnic identity. Empirical work using Phinney's (1992) Multigroup Ethnic Identity Measure (MEIM) delineated two important dimensions of ethnic identity: ethnic identity affirmation and ethnic identity exploration (Roberts et al., 1999). Ethnic identity affirmation refers to an individual's sense of belonging and attachment to the group, whereas ethnic identity exploration denotes the extent to which individuals have investigated and learned about their ethnic background by reading books, talking to other people about their ethnic group, and participating in cultural practices and activities.

Ethnic identity is one of the aspects of social identity that is of particular relevance to youth, especially Arab Americans. This aspect of identity draws attention to ethnic group membership (Phinney, 1990, 2003). Beliefs regarding one's ethnicity are crucial for the psychological wellbeing of Arab American youth, whose social groups are misrepresented, misperceived, held in low esteem, and often discriminated against. Ethnic identity may be the shield through which youth can assert themselves in the face of threats to their sense of self. The centrality of ethnic identity is attested to by various research studies indicating that a positive attitude toward one's ethnic group among youth is associated with positive developmental outcomes including academic success (Supple, Ghazarian, Frabutt, Plunkett, \& Sands, 2006), intrinsic motivation for learning (Okagaki, Frensch, \& Dodson, 1996), and increased self-esteem (Carlson, Uppal, \& Prosser, 2000; Costigan, Koryzma, Hua, \& Chance 2010; Umaña-Taylor, Gonzales-Backen, \& Guimond, 2009). A similar line of research has also found that ethnic identity may mitigate the negative effects of discrimination on the psychological wellbeing of various minority groups (e.g. Seaton, 2009; Sellers, Copeland-Linder, Martin, \& Lewis, 2006; Umaña-Taylor, Wong, Gonzales, \& Dumka, 2012), including Arab Americans (Fakih, 2014).

In relation to ethnic identity development, Phinney $(1989,1990,1996)$ proposed that members of all ethnic groups progress through three stages: ethnic identity diffusion/foreclosure (also referred to as unexamined), moratorium, and achievement. In the initial, unexamined stage, adolescents may not give much thought to what their ethnicity means. Alternatively, they may adopt the values and attitudes ascribed to their group as their own; in this case, adolescents do not examine issues related to their ethnicity for themselves; rather, attitudes from their parents or the dominant group toward their ethnic group are often passively adopted. The second stage, moratorium, is marked by an increased salience of ethnicity. Adolescents explore the meaning of their ethnicity by engaging in various activities, including reading books about their culture, associating with same-ethnicity peers, participating in cultural events, and joining ethnic youth organizations. Finally, during the third stage, achievement, adolescents develop a clearer understanding of what their ethnicity means to them and build a strong sense of affiliation with and affinity toward their ethnic group.

Identity, however, does not develop in a vacuum; there is a growing consensus in the theoretical and empirical literature that identity is not only multidimensional but also highly context dependent. The ecological systems theory put forward by Bronfenbrenner (1989) conceptualizes the context in which the adolescent develops as a set of nested structures including the microsystem, the exosystem, and the macrosystem. The microsystem encompasses the relationship individuals have with their immediate environment, such as relationships with parents and peers. The exosystem involves the more distal environments that may indirectly influence development; an important exosystem may include neighborhood characteristics (i.e. living in an ethnically dense community vs. living in more ethnically diverse communities). Finally, the macrosystem encompasses the larger sociocultural context and may include public policies, laws, customs, political beliefs, and mass media. In addition, central to this theory is the recognition that individual characteristics interact with contextual factors to influence development. Of particular relevance to Arab youth is the prevalence of gender differences in parental and community socialization practices, which may differentially inform the process of identity development. As such, drawing on Bronfenbrenner's ecological systems model helps review the proximal 
and distal factors that may either promote or obstruct the development of a positive identity among Arab American youth.

\section{Agents of Socialization for Arab American Youth Development}

The ecological model of human development highlights four agents of socialization that influence youth identity: family, peers/school, community, and the media. Each is proposed to exert an effect on youth development for Arab Americans.

\section{Family}

The family context, as a microsystem, represents the very first point of socialization for children. Identities gleaned from interactions between and among family members are especially salient for children. In Arab culture, a child's identity is very much influenced by the parent-child relationship (Beitin \& Aprahamian, 2014). One important value that children learn with regard to interpersonal relationships is to show respect for adults and to engage in hospitable, polite, and cordial behaviors when in the presence of guests (Nydell, 2006). Interactions that communicate to a child that he or she is an extension of the parent produce a feeling of intense closeness and connectedness in the Arab family (Joseph, 1999). It is common for a mother or father to refer to the child as 'eyouni (my eyes), mama, or baba. Open and frequent affectionate displays and verbalized expressions of endearment toward children by parents, grandparents, aunts, uncles, cousins, and other extended family members are common (Simon, 1996). As such, this socialization process begets a sense of self that is tightly connected to adults and other children in the family. Family socialization fosters a collective identity in which the individual is viewed as important, yet best understood in relation to close and significant others.

Within this family connectedness, children often begin to learn identities around both gender and ethnicity. Learning male and female identities is a universal experience, regardless of ethnic group membership. In the Arab American family context, however, the concept of patrilineality renders traditional aspects of a gendered identity central (Ajrouch, 1999; Beitin \& Aprahamian, 2014). Patrilineal family structure is a system of descent that entitles members to certain rights based on gender and also guarantees automatic family affiliation through the father (Aswad, 1988). This arrangement places enormous responsibility and simultaneous privilege on male members because it is men in the family who ensure security, maintain continuity of the family line, and provide a sense of belonging. Girls also learn responsibility toward the family in that their actions and behaviors have the potential to confer, or conversely challenge, family reputation and honor. As such, girls are often seen as valuable and in need of protection.

In the U.S. context, tensions sometimes arise between youth and parents, especially concerning daughters. Girls who learn to navigate between the culture of their parents and the dominant culture will undoubtedly benefit from both worlds (Ajrouch, 2005). However, situations may arise where girls embrace one culture over the other. Interestingly, these conflicting expectations often provide more opportunities for girls to choose various roles that include any combination of traditional and American opportunities (in the best of cases), while boys often get pushed into the role of economic provider (Ajrouch, 2004).

Learning what it means to be a boy and what it means to be a girl also has enormous influence on the meaning behind ethnic identity. The saliency of ethnicity becomes important as children reach adolescence. Adolescence fosters more opportunities to experience social life outside the family context. As a result, Arab American children learn that their taken-for-granted assumptions about how things are and should be do not necessarily represent the worldviews of others. Parental restrictions on girls during these years are especially indicative of factors that contribute to young people's sense 
of their ethnicity (Ajrouch, 1999, 2000, 2004). For instance, though dating is frowned upon generally, leniency toward boys is evident in that parents often turn a blind eye to their sons' dating activities, but directly prohibit it for their daughters. Moreover, other family members, including brothers, will actively ensure female family members do not date, often justifying their interference as a necessary part of their role as protector. It should be noted, however, that restrictions on girls' dating behaviors, thought to represent a kind of moral superiority to the dominant culture (see Espiritu, 2001), is not unique to Arab Americans, and seems to reflect the foundations of ethnic identity for many groups both today and historically (Ajrouch, 2004).

\section{Peers/School}

Interactions in school and with peers represent another key microsystem that influences various facets of identity. It should be noted that Arab Americans report relatively high academic achievement (Fakhoury, 2012; Tabbah, Miranda, \& Wheaton, 2012), as well as comparatively higher education levels than the majority of Americans (Read, 2004).Yet, a positive sense of self among Arab Americans appears more threatened in high school years compared to middle school years (Tabbah et al., 2012). Arab American identity issues arise concerning curriculum engagement, boy-girl interactions (dating), and immigrant-U.S.-born conflict.

Curriculum engagement concerns the ways in which schools present material during instruction, including topics chosen for lessons as well as peer reactions to the lesson topic. For instance, partial information or misinformation related to current and recent historical events that touch on Arabs coupled with minimal factual instruction about Arabs in the classroom often lead to teacher and students promulgating stereotypical images of Arabs, especially Arab women, as uneducated and oppressed (Mango, 2012). Though multicultural education continues to invite widespread debate (Modood, 2013), experiences such as the above have led to calls for inclusion of Arab Americans in school curricula. In particular, there is a perceived need to encourage teachers to address misrepresentations, and to empower all students, regardless of race or ethnicity, with the skills to recognize when thoughts of prejudice and acts of discrimination are being circulated (Mango, 2012; Tabbah et al., 2012; Wingfield, 2006).

The way in which curriculum material is presented and discussed in the school setting represents a critical issue for identity, but gender matters also arise as central to identity in peer and school interactions. Gendered elements of school and peer interactions become more prominent with the advent of institutionally sanctioned activities such as school dances. Dating activities become prominent during high school, and therefore gender relations emerge with sexual possibilities. With these developments, ethnic attributes may become the basis by which to separate groups. For instance, referencing the notion that Arab girls are not allowed to date, but "White" girls are, signifies a symbolic boundary shaped by gender relations (Ajrouch, 2004). Symbolic boundaries represented through beliefs about dating behavior serve to form, or reinforce, racial and ethnic group belonging. Experiences regarding identity are increasingly more gendered and the realization of being "Arab" becomes quite salient as youth reach adolescence (Ajrouch, 1999).

Though gender relations emerge as important to identities, experiences vary among Arab American youth, especially comparing those who are U.S.-born to immigrants. In a study of Arab American immigrant attitudes toward education, Fakhoury (2012) found that immigrant youth often encountered negativity from U.S.-born Arab Americans, shunned and not accepted into the social circles of those who were U.S.-born. Arab immigrant youth, often referred to as "boaters," have been described negatively by U.S.-born Arab Americans within the school setting (see Ajrouch, 2004). This dynamic may reflect the acculturation process, whereby the U.S. born, especially the second generation or children of immigrants, strive for American aspects of their identity by distancing themselves from immigrant culture (Ajrouch, 2000, 2004). In sum, the peer and school settings 
highlight the influence of curriculum, gender, and immigrant interactions as influential microsystems on identity for Arab American youth.

\section{Community}

Arab American communities are uniquely structured to serve many of the economic and social service needs of the children, adolescents, and families who reside within them. Taking an ecological systems approach (Bronfenbrenner, 1994), services for Arab youth in local organizations and multicultural community centers can be viewed as having an interactive influence and impact on the developing child and adolescent in conjunction with the influences of parents, peers, schools, neighborhoods, and religious institutions. For Arab Americans, these community centers, which may or may not include affiliations with religious institutions, are uniquely situated within major U.S. metropolitan areas of various states, including California, Michigan, Illinois, Pennsylvania, New York, and Washington, D.C., among others.

Important to the ego-identity of youth is how they feel they are perceived within their neighborhoods and communities, as well as within the broader society in which they live. One youth-focused community center is located in Philadelphia, Pennsylvania, and is called Al Bustan: Seeds of Change; "al bustan" means "the garden" in Arabic. The mission of Al Bustan is to promote the enculturation and cultural identity of Arab American youth through exposure to the language and cultural traditions of the Arab world, including music and the visual arts. The center aims to promote a positive self-image among Arab American youth, as well as disseminate celebrated cultural aspects to non-Arab youth. To broaden education about Arab culture, Al Bustan fosters inclusion of both Arab and non-Arab youth of various racial and ethnic backgrounds into its cultural programs, which involve learning the Arabic language, summer camp activities, and various art and music workshops and events. For example, Al Bustan held a video workshop in which Arab American adolescents were among participants who were given the opportunity to use film media to explore their sense of inclusion and belonging to American society given the challenges to their identities in the contemporary exclusionary sociopolitical climate (Abu El-Haj, 2009). The resulting films, which emphasized universal human values, rights, and issues related to the human need for inclusion and belonging, are available to educators through the $\mathrm{Al}$ Bustan website.

Like Al Bustan in Pennsylvania, opportunities for Arab youth to engage in community and religious events exist throughout the major metropolitan regions of the U.S. In addition to Christian churches (e.g. Maronite Catholic and Chaldean Catholic) and Islamic mosques that have primarily Arab congregations, there are community agencies such as the Arab Community Center for Economic and Social Services (ACCESS) in Michigan, the Arab American and Chaldean Council in Michigan, and the Arab American Family Support Center in New York. Arab heritage festivals, music performances, and Arab film festivals are among the events across America that are sponsored by these religious institutions and community agencies.

While at the local level the need for inclusion and belonging may be met for some Arab American youth through community programs and organizations, it is also the case that feelings of being excluded from the broader American society are experienced by many Arab American youth. Some Arab American youth are sensitive to the fact that media images often portray Arabs as "enemies" of America and as "terrorists" (Wray-Lake, Syvertsen, \& Flanagan, 2008). Fortunately, advocacy organizations such as the Arab American Institute in Washington, D.C., and the American-Arab Anti-Discrimination Committee promote Arab American youth understanding of issues around prejudice and discrimination through their educational campaigns, and foster youth participation in American political debates and discourse around social issues. Such organizations play a crucial role in promoting the wellbeing of first and second generation Arab American youth by counteracting the possible negative effects experienced from sociocultural adversities such as discrimination and the stress of acculturation within their neighborhoods and 
communities (Ahmed, Kia-Keating, \& Tsai, 2011). Though community support serves as a potentially influential resource, social support in general has been found to be an essential resource for Arab American youth in North America.

Social support can be provided within family, peer, and broader community contexts. For example, in their study of Muslim Arab American youth aged 11-15 years in metropolitan Detroit, Ramaswamy, Aroian, and Templin (2009) found that perceived social support from family members, school personnel, and friends showed a negative relation with self-reports of stressful daily hassles and internalizing problems such as depression and anxiety. Other studies have shown that Arab youth in Canada show beneficial psychological effects when they perceive social support from others within their social network (Abu-Laban \& Abu-Laban, 1999; Paterson \& Hakim-Larson, 2012). Moreover, Arab Canadian youth had more friends who were also relatives than did youth of other Canadian ethnic groups (Daniel, 2013). It may be that extended family and community networks are more readily accessible to Arab Canadians compared to other Canadian ethnic groups. Another possibility is Arab youth have reacted by favoring the comfort of their ingroup relationships given possible feelings of being socially excluded from the mainstream culture.

It should be noted, however, that though ethnic community contexts serve as an important refuge from the negative images and exclusionary sentiments felt through contact with American society, community living also exhibits social control of youth through gossip (see Ajrouch, 2000). These experiences serve to reinforce a strong sense of ethnic identity, but also sometimes propel youth to leave community settings in search of greater anonymity and less constraint. In sum, community, as an exosystem context, plays an influential role in the socialization and identity of Arab American youth. Next, a more omnipresent agent of socialization in the macrosystem that permeates beyond the physical and emotional space of community is considered: the media.

\section{Media}

Media play a role in socialization as a macrosytem influence. Media portrayals have enormous impact on group position, often serving as the only source of information about a group when personal contact has not occurred (see Blumer, 1958). For Arab Americans, media portrayals of their cultural group are underrepresented, yet when present, are overwhelmingly negative (Shaheen, 2009). Media coverage through news reports and entertainment venues rarely shows Arabs in a positive light. Media depictions also intersect with other contexts, such as peers and school settings, to impact Arab American youth. Indeed, the pervasiveness of negative images has been found to influence peer relations as early as elementary school. Arab American youth report that media coverage of 9/11 has led to them being called "terrorists" in the school setting (Kumar, Warnke, \& Karabenick, 2014). Those who have come of age in the twenty-first century face more visible and negative media portrayals in the aftermath of the attacks on the World Trade Center.

Another aspect of media that is important to consider involves consumption patterns. Rapid technological developments have led to a proliferation of media outlets. Indeed, media consumption among Arab American youth reflects habits of youth in general (Hernandez, 2012). Hernandez reported that as older Arab American youth access more media sources, including radio, online newspapers, magazines, and social networking sites, they are more likely to perceive their groups as negatively portrayed as compared to their younger counterparts. The absence of positive media portrayals poses genuine concern, as children often look to wider societal representations to emulate, especially as they increase social contact beyond the family context.

\section{Case Example: Social Influences on the Development of Alex and Ranya}

Arab American youth grow up in multiple contexts, each of which present various, sometimes conflicting expectations about their identities and sense of self. The case example that follows depicts a 
brother and sister, born in the late twentieth century to an immigrant father who has owned his own business since the age of 20 , and a U.S.-born mother with advanced education who worked as a university researcher. Alex Aboud was the first-born child, and for the first four years of his life he was an only child. His paternal grandfather, who lived approximately 20 minutes away, bestowed special grace on Alex, as the first-born child, through visits, attention, and gifts. In the traditional patrilineally organized Arab family, Alex represented the next generation family leader. Four years later, Alex's sister, Ranya, was born. Around the time that Ranya was born, Alex asked for a toy kitchen set. Alex's father became distressed, commenting that boys do not play with kitchen sets, to which Alex's mother replied that some of the greatest chefs in the world are men! Alex's mother bought him the kitchen set.

Striving to reject the special treatments allotted to boys with which she had grown up, Alex and Ranya's mother conscientiously strived to provide each child with equal opportunities and expectations. Alex developed an interest in politics at an early age through discussions with his father, and by the age of seven could recite every U.S. president forwards and backwards. When Ranya was three, she helped her mother box-up her baby clothes, and in that process was told by her mother that she should save an infant undershirt that said "Future U.S. President," because Ranya's father had bought it for her when she was still in her mother's stomach. Ranya opened her eyes wide in disbelief and asked, "Did daddy think I was going to be a boy?"

Though the children did not live in an ethnic enclave, they regularly visited relatives and friends who lived in a densely populated Arab American community, and also were highly active in transnational activities, visiting their parent's homeland of Lebanon at least once a year during the summer months. Their early education was at a private Montessori school, located in the midst of a metro-area suburb that was increasingly attracting Arab American families, but located 20 miles east of Alex and Ranya's home. At the Montessori school, both Alex and Ranya were taught about ethnic and cultural diversity, with difference identified as something to celebrate. For instance, school activities encouraged ethnic sharing, such as "pot lucks" where students brought food representative of their culture. Such events contributed to and highlighted positive elements of diversity, and in so doing contributed to building a sense of community. The school curriculum and peer interactions stressed equality, understanding, and solidarity.

Both Alex and Ranya eventually left the Montessori school to attend the public school in their homogenously "White" neighborhood. In September 2001, Alex was in middle school and Ranya in third grade. When the terrorist attack happened, Alex discussed with his parents what he would say to friends at school given that the terrorists were Arab Muslims. He came up on his own with the response, "though the terrorists were Arab Muslims, not all Arab Muslims are terrorists." Ranya did not feel the need to address the attacks in school, but a number of years later, when she was in middle school and on the volleyball team, she lost her pendant - with the Arabic word for God written on it - at a game. She came home quite upset because she had worn the pendant since she was a young child. When her mother suggested she ask the coach if anyone had found it, she cried in response: "How would I describe what I lost? That it says God in Arabic? They will think I am a terrorist!"

Though both children developed friendships with others from diverse backgrounds throughout their childhood, as they grew into adolescence they increasingly preferred to spend time with friends from their ethnic background. Upon entering college, both became highly involved in ethnic student organizations, but differed in the extent to which they shared their social activities with their parents. While Alex brought home girlfriends, Ranya never shared that she had a boyfriend. Perceiving that her father would not approve, she chose to keep that part of her life hidden from her parents and brother. Her brother, having observed peers in the ethnic community, made a point to question her on a regular basis about whom she would be with and where she planned to be, as a means to monitor her social activities.

As this case example illustrates, a sense of group belonging for older children and adolescents is critical to an overall sense of wellbeing. The importance of group belonging to wellbeing is supported 
by most developmental models that incorporate ego identity (e.g. Kegan, 1982; Loevinger \& Wessler, 1978). Several challenges to this feeling of group connectedness emerged for Alex, Ranya, and their family, however. Among these challenges were inconsistent expectations regarding how to fulfill gender role obligations, both as prescribed by their ethnic values as well as by the mainstream culture. Though Alex and Ranya's mother strived to practice gender equality, messages received from other systems of influence, including peers and community, played a role in shaping gender expectations concerning life goals and social relationships. Ranya, in particular, found herself negotiating cultural expectations learned through both her family and wider American society. Challenges were made, as well, regarding how to negotiate their ethnic identities while attempting to acculturate in an interpersonal climate of non-Arab peers, whom they suspected of unjust and unfair perceptions. Given these stressful circumstances, Arab American youth may retreat into the familiar territory of same ethnicity peers, where a supportive net is in place to help in shaping their identities.

\section{Critique}

The literature on Arab American youth focuses almost exclusively on middle and high school, as well as college settings. There are several possible reasons for the scant literature outside these contexts. First, the fact that the U.S. Census Bureau does not officially recognize Arab Americans as a minority group that is distinct from the majority "White" or Caucasian population (Samhan, 2014) means that Arab American youth are often classified with European American youth in research studies. This makes identifying Arab American youth in large data sets highly challenging, if not impossible. Some exceptions to this exist in Arab American ethnic enclave regions where it is possible to recruit through local community advertisements (e.g. Aroian, Templin, Hough, Ramaswamy, \& Katz, 2011; Ramaswamy et al., 2009). Another possible reason for the lack of research on Arab American youth outside school settings may be the general difficulty that researchers have in recruiting both parents and their children for studies given parental time constraints, the lack of incentives to participate, and language and literacy barriers. One way around this is for researchers to go into the homes and to use oral interview methodologies in Arabic for data collection, a method that was utilized by Aroian and colleagues (2011). For Arab American families to participate in studies, some education around the purpose and value of the research, the limitations of confidentiality, informed consent and assent issues are necessary but complicating features of the research process.

The Arab American population is heterogeneous and represents racially and ethnically diverse Arabic-speaking people from all of the 22 members of the League of Arab States, spanning the Middle East to the northern coast of Africa (Nydell, 2006). Thus, rather than engaging in pan-Arab ethnic gloss in future studies addressing Arab youth issues, it may be more constructive to focus on the specific national, ethnic, and religious backgrounds of youth. This is important given the unique sociopolitical backgrounds of families by country of origin (e.g. Egyptian Coptic youth, Iraqi Muslim youth, Lebanese Maronite youth, Palestinian Muslim youth, etc.).

Recently, attention has focused on the possible protective factors and the positive development of minority American youth (Cabrera, Beeghly, \& Eisenberg, 2012). Though not specific to Arab American youth, the special volume introduced by Cabrera and colleagues contains studies that identify possible relevant protective factors in need of further study. At the individual level, these include a young person's ability to self-regulate and maintain bicultural language skills that could potentially enhance their cognitive development. A strong ethnic identity has also been found to be an individual protective factor. At the family level, having positive relationships with family members, enhanced by maternal warmth and paternal involvement, were identified as potential protective factors. Finally, neighborhood and community supports that provide extra-curricular and after-school activities for youth were also suggested as potential protective factors.

Taking a biopsychosocial approach to healthy development in Arab American youth involves a consideration of which levels of analyses will yield the most fruitful results to understanding youth 
resilience in the face of psychosocial stressors and hardships (Hakim-Larson, Nassar-McMillan, \& Ajrouch, 2014). Masten (2007) identified five areas for understanding resilience in the developing individual.These are in the domains of religion/spirituality, family life, peer relationships, schools/teachers, and community/culture. Research on prevention that is meant to optimize the wellbeing of Arab American youth will need to take a multilevel systems approach, incorporating these five domains, to gain a more comprehensive picture of Arab youth functioning (Hakim-Larson et al., 2014).

\section{Conclusion}

This chapter used an ecological theoretical framework to organize what is known about Arab American youth, highlighting the ways that family, peers, community, and media influence youth development. For Arab American youth, socialization at various levels (from the micro- to exoto macrosystems influences development) both directly and in conjunction with one another. The potential for positive development may result from each, but in the face of possible strengths also lie challenges. Research has focused primarily on the adolescent years, leaving a dearth of information on early childhood development. Given that agents of socialization begin to influence development at birth, more systematic attention to the years before adolescence will address a gap in the field. Youth is an important point in the life course, increasingly seen as a period during which gender and ethnic identity emerge as key elements in daily interactions. Overall, this chapter has shown that Arab Americans as a group are increasingly more visible, though their diversity of experiences must be recognized in order to most effectively address developmental challenges and maximize success.

\section{References}

Abu El-Haj, T. (2009). Imagining postnationalism: Arts, citizenship education, and Arab American youth. Anthropology \& Education Quarterly 40(1), 1-19. doi: 10.1111/j.1548-1492.2009.01025.x

Abu-Laban, S. M. \& Abu-Laban, B. (1999). Teens between: The public and private spheres of Arab-Canadian adolescents. In M. W. Suleiman (ed.), Arabs in America: Building a new future (pp.113-128). Philadelphia, PA: Temple University Press.

Ahmed, S. R., Kia-Keating, M., \& Tsai, K. H. (2011). A structural model of racial discrimination, acculturative stress, and cultural resources among Arab American adolescents. American Journal of Community Psychology 48(3-4), 181-192. doi: 10.1007/s10464-011-9424-3

Ajrouch, K. J. (1999). Family and ethnic identity in an Arab American community. In M. Suleiman (ed.), Arabs in America: Building a new future (pp. 129-139). Philadelphia, PA: Temple University Press.

Ajrouch, K. J. (2000). Place, age, and culture: Community living and ethnic identity among Lebanese American adolescents. Small Group Research 31,447-469. doi: 10.1177/104649640003100404

Ajrouch, K.J. (2004). Gender, race, and symbolic boundaries: Contested spaces of identity among Arab American adolescents. Sociological Perspectives 47, 371-391. doi: 10.1525/sop.2004.47.4.371

Ajrouch, K. J. (2005). Women, gender and youth culture and movements: United States. In S. Joseph (ed.), Encyclopedia of women and gender in Islam (vol. 2, pp. 795-798). Netherlands: Brill Publishers.

Aroian, K. J., Templin, T. N., Hough, E. E., Ramaswamy,V., \& Katz, A. (2011). A longitudinal family-level model of Arab Muslim adolescent behavior problems. Journal of Youth and Adolescence 40, 996-1011. doi: 10.1007/ s10964-010-9615-5

Aswad, B. (1988). Strengths of the Arab family for mental health considerations and therapy. In I. Ahmed \& N. Gray (eds.), The Arab American family: A resource manual for human service providers (pp. 93-101). Lansing, MI: Eastern Michigan University and ACCESS.

Beitin, B. K. \& Aprahamian, M. (2014). Family values and traditions. In S. C. Nassar-McMillan, K. J. Ajrouch, \& J. Hakim-Larson (eds.), Biopsychosocial perspectives on Arab Americans: Culture, development and health (pp. 67-88). New York: Springer. doi: 10.1007/978-1-4614-8238-3_4

Blumer, H. (1958). Race prejudice as a sense of group position. Pacific Sociological Review 1(1), 3-7. doi: 10.2307/ 1388607

Bronfenbrenner, U. (1989). Ecological systems theory. In R. Vasta (ed.), Annals of child development (vol. 6, pp. 187-249). Greenwich, CT: JAI Press.

Bronfenbrenner, U. (1994). Ecological models of human development. In T. N. Postlethwaite \& T. Husen (eds.), International Encyclopedia of Education (2nd edn., vol. 3, pp. 1643-1647). Oxford: Elsevier. 
Cabrera, N. J., Beeghly, M., \& Eisenberg, N. (2012). Positive development of minority children: Introduction to the special issue. Child Development Perspectives 6, 207-209. doi: 10.1111/j.1750-8606.2012.00253.x

Cainkar, L. (2009). Homeland insecurity: The Arab American and Muslim American experience after 9/11. New York: Russell Sage Publications.

Carlson, C., Uppal, S., \& Prosser, E. C. (2000). Ethnic differences in processes contributing to the self-esteem of early adolescent girls. The Journal of Early Adolescence 20, 44-67. doi: 10.1177/0272431600020001003

Costigan, C. L., Koryzma, C. M., Hua, J. M., \& Chance, L. J. (2010). Ethnic identity, achievement, and psychological adjustment: Examining risk and resilience among youth from immigrant Chinese families in Canada. Cultural Diversity and Ethnic Minority Psychology 16, 264-273. doi: 10.1037/a0017275

Daniel, S. (2013). Immigrant and non-immigrant youth in Canada: Cultural orientation, ethnicity of friends, and life satisfaction among four ethnic groups (Master's thesis). Available from ProQuest Dissertations and Theses database (UMI No. MR87354).

De Haan, L. G. \& Schulenberg, J. (1997). The covariation of religion and politics during the transition to young adulthood: Challenging global identity assumptions. Journal of Adolescence 20, 537-552. doi: 10.1006/ jado.1997.0108

Erikson, E. H. (1968). Identity: Youth and crisis (1st edn.). New York: Norton.

Espiritu,Y. (2001). "We don't sleep around like white girls do": Family, culture, and gender in Filipina American lives. Signs 26(2), 415-440. doi: 10.1086/495599

Fakhoury, N. (2012). Academic achievement and attitudes of Arab-American immigrants (Master's thesis). Available from ProQuest Dissertations and Theses database (UMI No. 1533342).

Fakih, R. R. (2014). Ethnic identity among Arab Americans: An examination of contextual influences and psychological well-being (Doctoral dissertation). Available from ProQuest Dissertations and Theses database (UMI No. $3613203)$.

Goossens, L. (2001). Global versus domain-specific statuses in identity research: A comparison of two self-report measures. Journal of Adolescence 24, 681-699. doi: 10.1006/jado.2001.0438

Hakim-Larson, J., Nassar-McMillan, S. C., \& Ajrouch, K. J. (2014). Health and well-being in Arab Americans: Prevention strategies using a biopsychosocial approach. In S. C. Nassar-McMillan, K. J. Ajrouch, \& J. Hakim-Larson (eds.), Biopsychosocial perspectives on Arab Americans: Culture, development, and health (pp. 387-401). New York: Springer. doi: 10.1007/978-1-4614-8238-3_18

Hernandez, P. A. (2012). Muslim American youth and media (Doctoral dissertation). Available from ProQuest Dissertations and Theses database (UMI No. 3508762).

Joseph, S. (ed.) (1999). Intimate selving in Arab families: Gender, self, and identity. Syracuse, NY: Syracuse University Press.

Kegan, R. (1982). The evolving self: Problem and process in human development. Cambridge, MA: Harvard University Press.

Kroger, J. (2003). Identity development during adolescence. In G. R. Adams \& M. D. Berzonsky (eds.), Blackwell handbook of adolescence (pp. 205-226). Malden, MA: Blackwell Publishing.

Kumar, R., Warnke, J. H., \& Karabenick, S. A. (2014). Arab-American male identity negotiations: Caught in the crossroads of ethnicity, religion, nationality and current contexts. Social Identities: Journal for the Study of Race, Nation and Culture 20, 22-41. doi: 10.1080/13504630.2013.864464

Lazarus, R. S. (1991). Emotion \& adaptation. New York: Oxford University Press.

Loevinger, J. \& Wessler, R. (1978). Measuring ego development. San Francisco, CA: Jossey-Bass.

Mango, O. (2012). Arab American women negotiating identities. International Multilingual Research Journal 6, 83-103. doi: 10.1080/19313152.2012.665823

Marcia, J. E. (1966). Development and validation of ego-identity status. Journal of Personality and Social Psychology 3, 551-558. doi: 10.1037/h0023281

Marcia, J. E. (1980). Identity in adolescence. In J. Adelson (ed.), Handbook of adolescent psychology (pp. 159-187). New York: John Wiley.

Masten,A. S. (2007). Resilience in developing systems: Progress and promise as the fourth wave rises. Development and Psychopathology 19, 921-930. doi: 10.1017/S0954579407000442

Modood,T. (2013). Multiculturalism (2nd edn.). Malden, MA: Polity Press.

Nydell, M. K. (2006). Understanding Arabs: A guide for modern times (4th edn.). Boston, MA: Intercultural Press.

Okagaki, L., Frensch, P.A., \& Dodson, N. E. (1996). Mexican American children's perceptions of self and school achievement. Hispanic Journal of Behavioral Sciences 18, 469-484. doi: 10.1177/07399863960184003

Paterson, A. D. \& Hakim-Larson, J. (2012). Arab youth in Canada: Acculturation, enculturation, social support, and life satisfaction. Journal of Multicultural Counseling and Development 40, 206-215. doi: 10.1002/j.2161-19 12.2012.00018.x

Phinney, J. S. (1989). Stages of ethnic identity development in minority group adolescents. The Journal of Early Adolescence 9(1-2), 34-49. doi: 10.1177/0272431689091004 
Phinney, J. S. (1990). Ethnic identity in adolescents and adults: Review of research. Psychological Bulletin 108, 499-514. doi: 10.1037/0033-2909.108.3.499

Phinney, J. S. (1992). The Multigroup Ethnic Identity Measure: A new scale for use with diverse groups. Journal of Adolescent Research 7, 156-176. doi: 10.1177/074355489272003

Phinney, J. S. (1996). Understanding ethnic diversity: The role of ethnic identity. American Behavioral Scientist 40, 143-152. doi: 10.1177/0002764296040002005

Phinney, J. S. (2003). Ethnic identity and acculturation. In K. M. Chun, P. Balls Organista, \& G. Marín (eds.), Acculturation: Advances in theory, measurement, and applied research (pp. 63-81). Washington, D.C.: American Psychological Association.

Ramaswamy, V., Aroian, K. J., \& Templin, T. (2009). Adaptation and psychometric evaluation of the multidimensional scale of perceived social support for Arab American adolescents. American Journal of Community Psychology 43(1-2), 49-56. doi: 10.1007/s10464-008-9220-x

Read, J. G. (2004). Culture, class, and work among Arab-American women. New York: LFB Scholarly Publishing LLC.

Roberts, R. E., Phinney, J. S., Masse, L. C., Chen,Y. R., Roberts, C. R., \& Romero, A. (1999). The structure of ethnic identity of young adolescents from diverse ethnocultural groups. The Journal of Early Adolescence 19, 301-322. doi: 10.1177/0272431699019003001

Samhan, H. H. (1999). Not quite white: Race classification and the Arab-American experience. In Michael W. Suleiman (ed.), Arabs in America: Building a new future (pp. 209-226). Philadelphia, PA: Temple University Press.

Samhan, H. H. (2014). Intra-ethnic diversity and religion. In S. C. Nassar-McMillan, K. J. Ajrouch, \& J. Hakim-Larson (eds.), Biopsychosocial perspectives on Arab Americans: Culture, development, and health (pp. 45-65). New York: Springer. doi: 10.1007/978-1-4614-8238-3_3

Seaton, E. K. (2009). Perceived racial discrimination and racial identity profiles among African American adolescents. Cultural Diversity and Ethnic Minority Psychology 15, 137-144. doi: 10.1037/a0015506

Sellers, R. M., Copeland-Linder, N., Martin, P. P., \& Lewis, R. L. H. (2006). Racial identity matters: The relationship between racial discrimination and psychological functioning in African American adolescents. Journal of Research on Adolescence 16, 187-216. doi: 10.1111/j.1532-7795.2006.00128.x

Shaheen, J. G. (2009). Reel bad Arabs: How Hollywood vilifies a people. Northampton, MA: Olive Branch Press.

Simon, J. P. (1996). Lebanese families. In M. McGoldrick, J. Giordano, \& J. K. Pearce (eds.), Ethnicity and family therapy (2nd edn., pp. 364-375). New York: Guilford.

Sirin, S. R. \& Balsano, A. B. (2007). Editor's introduction: Pathways to identity and positive development among Muslim youth in the West. Applied Developmental Science 11, 109-111. doi: 10.1080/10888690701454534

Sirin, S. R., Bikmen, N., Mir, M., Fine, M., Zaal, M., \& Katsiaficas, D. (2008). Exploring dual identification among Muslim-American emerging adults: A mixed methods study. Journal of Adolescence 31, $259-279$. doi: 10.1016/j.adolescence.2007.10.009

Supple, A. J., Ghazarian, S. R., Frabutt, J. M., Plunkett, S. W., \& Sands, T. (2006). Contextual influences on Latino adolescent ethnic identity and academic outcomes. Child Development 77, 1427-1433. doi: 10.1111/j.1467-8 624.2006.00945.x

Tabbah, R., Miranda, A. H., \& Wheaton, J. E. (2012). Self-concept in Arab American adolescents: Implications of social support and experiences in the schools. Psychology in the Schools 49, 817-827. doi: 10.1002/pits.21640

Tajfel, H. (1978). The social psychology of minorities. London: Minority Rights Group.

Tajfel, H. (1981). Human groups and social categories: Studies in social psychology. Cambridge, England: Cambridge University Press.

Tajfel, H. \& Turner, J. C. (1986). The social identity theory of intergroup behavior. In S. Worchel \& W. G. Austin (eds.), Psychology of intergroup relations (pp. 7-24). Chicago, IL: Nelson-Hall Publishers.

Umaña-Taylor, A. J., Gonzales-Backen, M. A., \& Guimond, A. B. (2009). Latino adolescents' ethnic identity: Is there a developmental progression and does growth in ethnic identity predict growth in self-esteem? Child Development 80, 391-405. doi: 10.1111/j.1467-8624.2009.01267.x

Umaña-Taylor, A. J., Wong, J. J., Gonzales, N. A., \& Dumka, L. E. (2012). Ethnic identity and gender as moderators of the association between discrimination and academic adjustment among Mexican-origin adolescents. Journal of Adolescence 35, 773-786. doi: 10.1016/j.adolescence.2011.11.003

Wingfield, M. (2006). Arab Americans: Into the multicultural mainstream. Equity \& Excellence in Education 39, 253-266. doi: 10.1080/10665680600788453

Wray-Lake, L., Syvertsen, A. K., \& Flanagan, C. A. (2008). Contested citizenship and social exclusion: Adolescent Arab American immigrants' views of the social contract. Applied Developmental Science 12(2), 84-92. doi: 10.1080/10888690801997085 